\title{
Penggunaan Geotextil Sebagai Bahan Bangunan
}

\author{
*Fransiskus Xaverius Ndale ${ }^{1}$ \\ ${ }^{1}$ Program Studi Teknik Sipil, Fakultas Teknik, Universitas Flores, Ende, NTT \\ *)Correspondence e-mail:info@ferryndalle.com
}

\begin{abstract}
ABSTRAK
Bahan dasar geotekstil pada umumnya dihasilkan dari serat dan benang polymeric dengan unsur utama seperti polypropylene, polyester, polyethylene dan polyamide. Jenis geotextile yang banyak digunakan adalah jenis woven dan nonwoven Woven geotextiles adalah suatu bahan seperti kain yang dibentuk dengan ditenun. Nonwoven dibuat dengan 100 persen polypropylene. Bahan polimer sebagai perkuatan konstruksi, khususnya perkuatan dengan bahan geotextile. Geotextile merupakan salah satu jenis geosynthetis yang cukup luas penggunaannya dibidang teknik sipil untuk memecahkan permasalahan geoteknik. Sebagai alternatif yang digunakan dalam menangani tanah dasar adalah penggunaan geotekstil yang berfungsi sebagai pemisah atau separator (separation) ,filtrasi,drainase,perkuatan atau tulangan (reinforcement),stabilisasi,proteksi dan gabungan dari fungsi-fungsi tersebut. Dalam pemilihan bahan geotextil yang akan digunakan pada umumnya berdasarkan karakteristik teknik bahan geotextile tersebut. Karakteristik teknik tersebut meliputi antara lain karakteristik fisis, mekanis, dan hidrolis. Penggunaan geotextile yang paling umum diantaranya:stabilisasi tanah,perkuatan tanah timbunan,perkuatan lapis perkerasan jalan,perkuatan jalan kereta api,selain itu hasil pengembangan geotekstil dengan bahan lain: retaining wall, geotextile pada abutment jembatan,geotextile yang digunakan untuk box culvert,sedimen kontrol,waste containment. Hasil yang diperoleh dari penggunaan bahan geotekstil adalah: durabilitas bangunan dan umur bangunan lebih lama, pelaksanaan relatif mudah, bahan ringan mobilisasi relative murah, biaya konstruksi relative murah.
\end{abstract}

Kata Kunci: Geosynthetis, Geotekstil, Polymer, Reinforcement,

\section{PENDAHULUAN}

Perkembangan bahan-bahan konstruksi sangat diperlukan baik itu bahan alami maupun bahan buatan. Perkembangaan bahan tersebut meningkat seiring dengan kebutuhan manusia baik itu sebagai bahan utama dalam suatu struktur maupun sebagai bahan pendukung. Berbagai macam bahan yang biasa dipergunakan dalam konstruksi seperti beton, baja, kayu dan tidak ketinggalan sekarang bahan-bahan dari polimer (Plastics).

Polimer adalah bahan-bahan yang mempunyai berat molekul yang besar, struktur dan sifat-sifat yang rumit. Polimer ini rata-rata memiliki berat atom diatas 10.000. Molekul-molekul pembentuk polimer membentuk struktur-struktur rantai yang terikat satu sama lain.

Pada umumnya polimer (organic) dapat diklasifikasikan sebagai berikut :

1) Thermoplastics

Bahan thermoplastics ini terdiri dari termoplastik alami (natural) dan termoplastik buatan (synthetic) yang apabila diberikan peningkatan suhu akan menjadi lunak/mencair dan setelah pendinginan mengeras kembali. Bahan termoplastik alami antara lain : aspal, bitumen, pitches dan resin

2) Thermosetting plastics

Bahan-bahan termoseting plastic ini menjadi keras/mengeras dikarenakan perubahan atau pertukaran kimia unsur pembentuk dengan melakukan pemanasan dan diberikan katalisator atau dengan keduaduanya.

3) Chemically setting plastics

Bahan-bahan ini merupakan bahan yang dapat mengeras dengan penambahan bahan kimia dalam struktur molekul pembentuk.

\section{Sifat Bahan Polimer}

Sifat-sifat bahan polimer pada umumnya adalah sebagai berikut: 
1) Kemampuan cetak yang baik, sehingga menyebabkan ongkos pembuatan lebih rendah daripada logam dan keramik.

2) Produk yang ringan dan kuat dapat dibuat. Berat jenis polmer rendah dibandingkan dengan logam dan keramik yaitu $1,0-1,7$.

3) Polimer banyak yang bersifat isolasi listrik

4) Ketahanan air dan zat kimia cukup baik

5) Produk-produk dengan sifat yan cukup berbeda dapat dibuat tergantung pada cara pembuatan. Dengan mencampur zat pemplastis atau perkuataan seperti contoh plastic diperkuat oleh serat gelas $(F R P=$ Fiberglass reinforced plastics $)$

6) Umumnya bahan polimer lebih murah

7) Beberapa bahan tahan abrasi, atau mempunyai gesek yang kecil seperti dalam penggunaan geotekstile.

Sebagai alternatif dalam perancangan konstruksi sipil dengan menggunakan geotekstil, maka fungsi geotekstil yang nantinya akan diaplikasikan harus ditetapkan terlebih dahulu, setelah itu baru pilih tipe material yang cocok dengan berdasarkan sifat-sifat bahan geotekstil tersebut diatas.

Geotextile merupakan salah satu jenis geosynthetis yang cukup luas penggunaannya dibidang teknik sipil untuk memecahkan permasalahan geoteknik. Beberapa contoh pekerjaan di bidang teknik sipil yang berhubungan dengan tanah adalah: pekerjaan kontruksi jalan raya,pekerjaan saluran drainase,pekerjaan timbunan tanah,pekerjaan perkuatan dinding penahan tanah,masalah yang sering dihadapi dalam pekerjaan tersebut adalah dimana kondisi tanah dasar lunak dengan kapasitas daya dukung terhadap beban yang rendah.

\section{TEORI DASAR BAHAN}

Bahan dasar geotextile pada umumnya adalah dihasilkan dari serat dan benang polymeric dengan unsur utama seperti polypropylene, polyester, polyethylene dan polyamide. Namun demikian serat buatan seperti cellulose dan rayon juga banyak digunakan. Sebagian dari bahan geoshyntetics bahkan juga menggunakan bahan serat alami seperti kapas dan jute (bahan karung goni) sebagai bahan campuran serat.

\section{Jenis geotekstil}

Jenis geotekstil yang banyak digunakan adalah jenis woven dan nonwoven. Woven geotextiles adalah suatu bahan seperti kain yang dibentuk dengan ditenun. Nonwoven dibuat dengan 100 persen polypropylene.

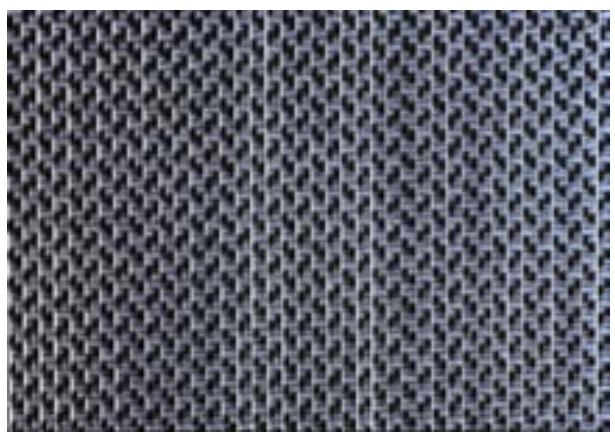

a? Non Woven

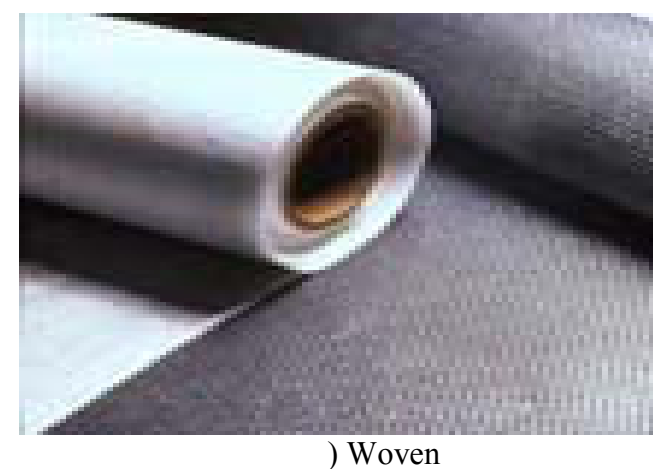

) Woven

Gambar 1. Jenis Geotekstil 
Woven geotextile ini biasa dipergunakan separator material konstruksi, perkuatan tanah dan pembagian beban. Bahan woven memiliki kekuatan kuat tarik tinggi tapi regangan kecil dan perubahan panjang terbatas pada pembebanan $(15 \%)$.



\section{Gambar 2. A Typical Woven Geotextile(Enlarged View)}

Non-woven geotextile bahan yang terbentuk acak tidak beraturan yang banyak digunakan sebagai soil separator, stabilisasi tanah, pembagian beban. Bahan ini untuk perkuatan retaining walls jarang digunakan.

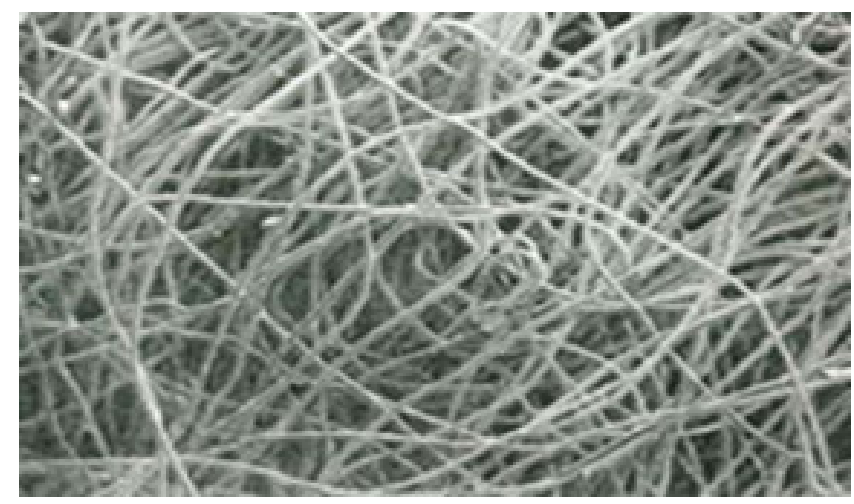

Gambar 3. A Typical Non-Woven Geotextile (Enlarged View)

\section{Karakteristik Geotekstil}

Dalam pemilihan bahan geotekstil yang akan digunakan pada umumnya berdarkan karakteristik teknik bahan geotekstil tersebut. Karakteristik teknik tersebut meliputi antara lain karakteristik fisis, mekanis, dan hidrolis.

Karakteistik fisis meliputi :berat,ketebalan, dan berat satuan atau juga berat jenis. Berat dan ketebalan bahan biasanya merupakan suatu bagain dari kekuatan bahan. Makin tinggi kekuatan bahan biasanya makin berat dan tebal bahannya. Berat jenis bahan diperlukan kadang-kadang untuk mengetahui apakah bahan tersebut tenggelam atau mengapung dalam air. Hal ini terutama untuk pekerjaan dibawah air.

Karakteristik mekanis merupakan karakteristik yang sangat penting untuk perencanaan. Karakteristik mekanis ini meliputi : kekuatan tarik (tensile strength),kekuatan pecah (brust strength),kekuatan robek (tear strength) dan kekuatan geser terhadap bahan butiran tanah.

Karakteristik hidrolis biasanya perlu diketahui apabila geotekstil yang akan digunakan berfungsi sebagai filter dan drainase. 


\section{METODE}

Beberapa peraturan yang dapat digunakan dalam penggunaan geotekstil adalah sebagai berikut:

\section{Tabel 1. Peraturan SNI tentang Geotekstil}

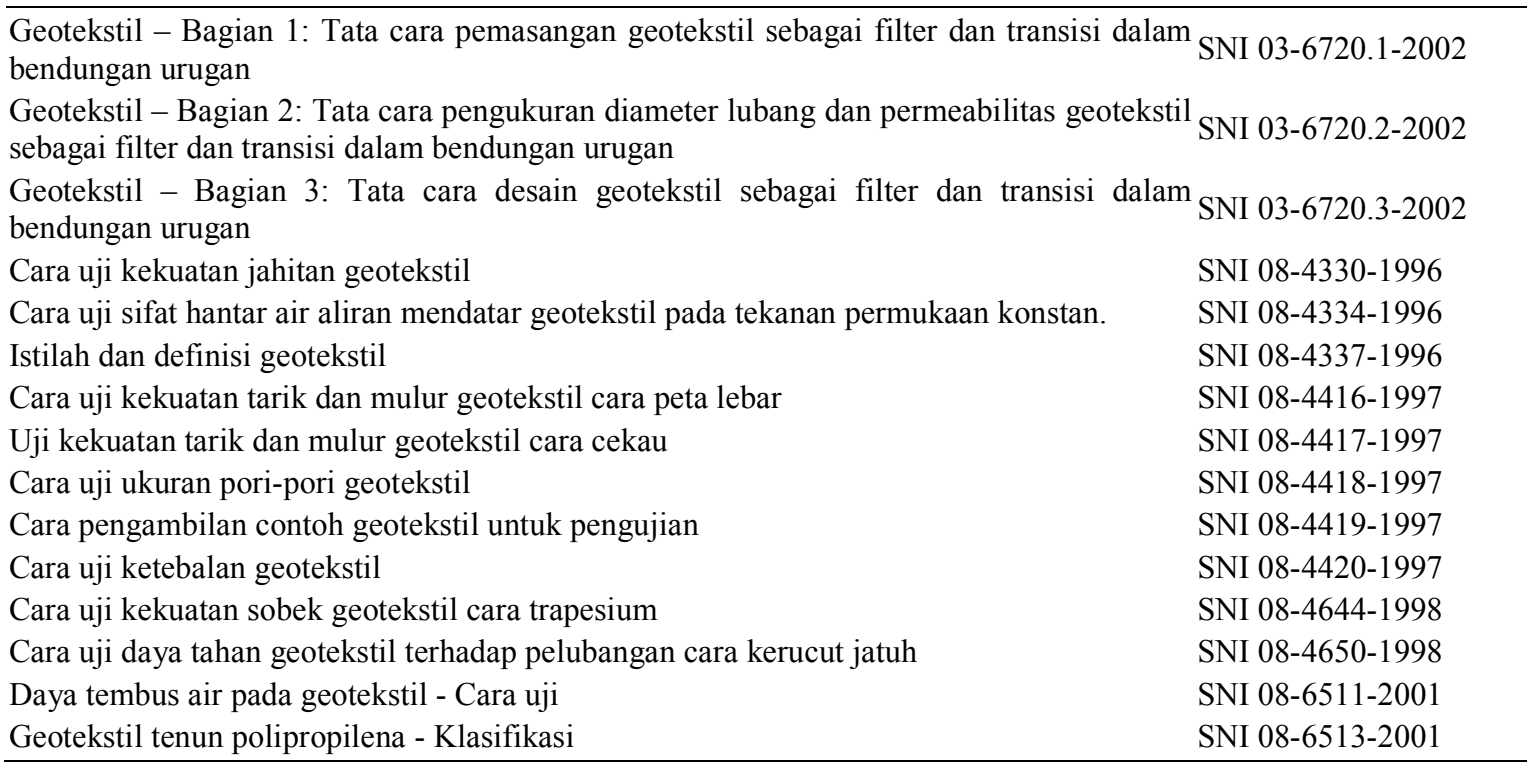

\section{HASIL DAN PEMBAHASAN}

Geotekstil ini telah banyak digunakan dalam berbagai hal baik itu sebagai struktur pendukung maupun sebagai struktur utama. Beberapa Negara maju seperti Amerika, Australia dan Negara-negara Eropa telah memiliki pabrik-pabrik geotekstil yang dapat diaplikasikan dalan bebagai struktur bangunan.

Dalam melakukan perancangan konstruksi sipil dengan menggunakan geotekstil, maka fungsi geotekstil yang nantinya akan diaplikasikan harus ditetapkan terlebih dahulu, setelah itu baru pilih tipe material yang cocok.

Fungsi - fungsi geotekstil meliputi :1)Pemisah atau separator (separation),2) Filtrasi,3) Drainase,4) Perkuatan atau tulangan (reinforcement),5) Stabilisasi,6) Proteksi, 7) Gabungan dari fungsi-fungsi tersebut

\section{Fungsi Pemisah atau Separator}

Prinsip dasar bahwa tanah dengan variasi ukuran dan distribusi yang berbeda tidak dapat diletakkan secara bersamaan. Butiran tanah yang berukuran lebih kecil akan cenderung berpindah ke dalam rongga pori tanah yang butirannya lebih besar. Kondisi lainnya, jika kekuatan tanah berbutir lebih halus yang lebih rendah terletak di bawah tanah yang berbutir kasar yang kekuatannya lebih tinggi, maka tanah yang berbutir kasar akan terpenetrasi ke dalam tanah yang butirannya lebih halus yang diakibatkan oleh beban diatasnya. Intrusi satu sama lain dari dua macam tanah yang berbeda gradasinya dapat mengakibatkan permasalahan yang dapat merugikan di dalam sistem tanah, seperti : 1) Mengganggu sistem drainase,2) Tanah lebih mudah berdeformasi,3) Umur struktur menjadi berkurang,4) Kekuatan tanah berkurang,5) Kemungkinan terjadinya kegagalan struktur menjadi lebih besar. Untuk menangani permasalahan tersebut, penggunaan material pemisah di antara dua jenis tanah yang berdekatan sangat dibutuhkan.

Pemasangan geotekstil sebagai pemisah di antara dua material yang berbeda akan menjaga integritas kedua tanah, sehingga kedua tanah yang berbeda tetap merupakan bahan yang utuh dan hasilnya sistem yang diberikan geotekstil tersebut akan menjadi lebih kuat. Geotekstil ini diletakan diantara dua lapisan tanah yang berbeda atau diletakkan antara tanah dasar dan tanah timbunan. Koerner (2005) 
mengilustrasikan perbedaan mekanisme gerakan butiran akibat penggunaan geotekstil pada tanah dasar lunak yang berfungsi sebagai pemisah ditunjukan pada Gambar 4



\section{Gambar 4 Aplikasi Geotekstil Sebagai Fungsi Pemisah pada Jalan Kereta Api}

Geotekstil yang digunakan untuk fungsi pemisah ini umumnya tidak mempunyai kekuatan tarik yang tinggi, sehingga tidak cocok digunakan untuk perkuatan timbunan tinggi atau beban lalu lintas tinggi. Produk geotekstil yang cocok yaitu Non Woven Geotekxtile.

\section{Fungsi Filtrasi}

Dalam hal fungsi filtrasi, geotekstil harus dapat berfungsi sebagai filter yang memberikan kemungkinan adanya gerakan cairan yang melewatinya, yaitu aliran tegak lurus arah bidang lembarannya. Pada saat yang bersamaan, geotekstil juga harus bisa menahan tanah pada bagian hulunya agar butiran tanah tidak ikut bersamaan dengan aliran air. Oleh sebab itu, dua faktor penting yang harus dimiliki oleh geotekstil sebagai filtrasi yaitu :

a) Permeabilitas harus cukup besar (membutuhkan ukuran lubang bukaan pori-pori geotekstil). Geotekstil sebagai filter harus memberikan keleluasaan air mengalir melewatinya sampai umur rencana konstruksi.

b) Kemampuan geotekstil dalam menahan butiran tanah, agar tanah tidak ikut dalam aliran air (membutuhkan susunan benang-benang yang rapat) dan mencegah migrasi (piping) butiran tanah melewati geotekstil. Jika beberapa butiran halus melewati geotekstil, maka butiran tidak boleh menyumbat material di bagian hilir filter selama umur dari konstruksi.

Distribusi ukuran butir tanah yang akan disaring harus disesuaikan dengan distribusi ukuran lubang bukaan pori-pori geotekstil. Non woven geotextile umumnya cocok digunakan sebagai filter untuk berbagai jenis tanah dengan sebaran butiran yang luas.

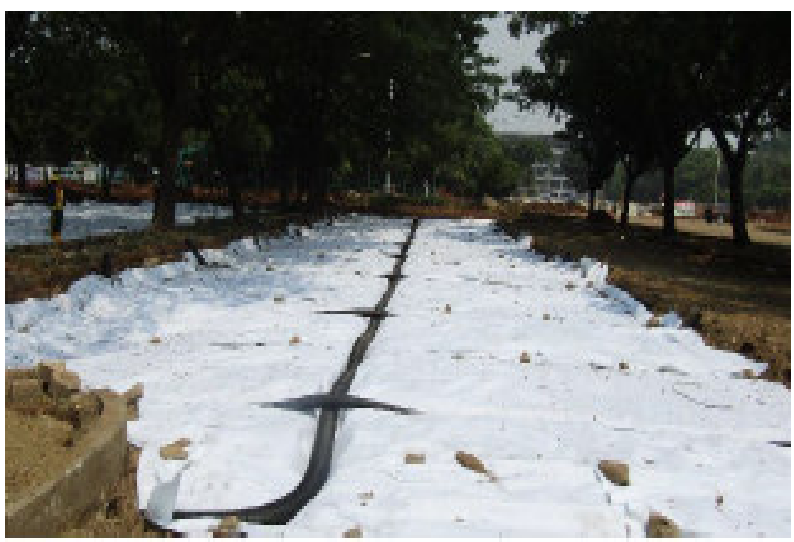

Gambar 5 Aplikasi Geotekstil Sebagai Fungsi Filtrasi 
Sebagai fungsi filtrasi, geotekstil harus mempunyai permeabilitas yang tinggi. Pertimbangan lain bahwa geotekstil harus lolos air adalah untuk mencegah adanya tekanan air (gaya angkat) dalam struktur yang akan mengurangi stabilitas.

Bila geotekstil digunakan sebagai filter, air harus bisa mengalir melewati geotekstil menuju ke kerikil atau batuan, pipa, maupun sistem drainase lainnya. Permeabilitas arah melintang geotekstil umumnya mencukupi untuk drainase dalam tanah yang baik. Pengecualiannya, adalah jika geotekstil digunakan di bawah struktur pengendali erosi (rip-rap atau blok-blok beton). Dalam kasus ini, blok-blok material mungkin dapat menutupi geotekstil, dan jika terhamburnya tekanan air pori dengan cepat maka, kegagalan (dapat berupa sobeknya permukaan geotekstil) dapat terjadi.

Nilai permeabilitas tidak mutlak, karena tebal geotekstil seiring dengan berjalannya waktu dapat berubah oleh adanya beban. Karena itu, permeabilitas geotekstil dinyatakan dalam rasio permeabilitas terhadap tebal lembaran geotekstil disebut dengan istilah permetivitas.

\section{Fungsi Drainase}

Geotekstil pada arah bidangnya dapat dialiri oleh cairan sehingga dapat berfungsi sebagai drainase. Fungsi drainase dalam geotekstil sebagai keseimbangan dalam sistem geotekstil terhadap tanah, yang memungkinkan aliran yang bebas mengalir (tapi tidak ada tanah yang hilang) searah bidangnya pada periode waktu yang panjang (Koerner, 1990). Fungsi drainase geotekstil umumnya berkurang bila tegangan normal yang bekerja pada bidangnya bertambah. Aliran cairan searah bidang geotekstil diistilahkan sebagai transmissivitas.

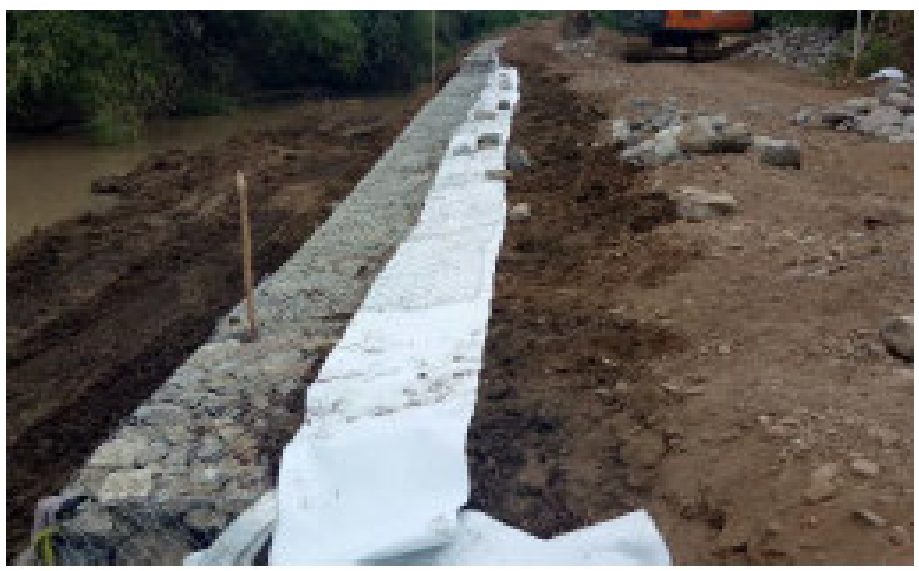

Gambar 6 Aplikasi Geotekstil Sebagai Fungsi Drainase

Kemampuan geotekstil untuk mengalirkan air searah bidang merupakan keuntungan lain, disamping kemampuan mengalirkan air ke arah normalnya dalam aplikasi geotekstil untuk drainase. Aplikasi drainase searah bidang ini misalnya geotekstil digunakan untuk :

a) Drainase pemotong (interceptor drain).

b) Pengaliran air di bawah tanah lapisan pondasi jalan raya.

c) Drainase pita horizontal dan vertikal untuk mempercepat proses konsolidasi.

d) Pelepasan tekanan air pori dalam lereng tanah atau batuan.

e) Pelepas tekanan air pori dalam timbunan dan bendungan dan lain-lain.

Geotekstil mempunyai kemampuan mengalirkan air searah bidangnya, contohnya non woven geotextile tipe needle punched. Lebih sering digunakan untuk aplikasi drainase.

\section{Fungsi Tulangan (Reinforcmenet)}

Fungsi reinforcement (perkuatan) pada geosintetik dapat diterjemahkan sebagai fungsi tulangan, seperti istilah pada beton bertulang (reinforced concrete). Tanah hanya memiliki kekuatan untuk menahan beban tekan, tetapi tidak dapat menahan beban tarik. Kelemahan terhadap tarik ini dipenuhi oleh geotekstil. 
Geotekstil yang mempunyai kemampuan menahan tarik dapat memberikan perkuatan dalam bentuk tulangan. Material ini dapat diletakkan di bawah timbunan yang di bangun di atas tanah lunak, dapat digunakan untuk membangun dinding penahan tanah, dan dapat juga digunakan untuk perkuatan bahan susun pekerasan jalan beserta tanah dasarnya.

Geotekstil sebagai tulangan memberikan kuat tarik dan kekakuan. Deformasi geotekstil adalah syarat awal agar terjadi transfer tegangan. Akibatnya, untuk mencapai fungsi perkuatan dari tulangan, dibutuhkan transfer beban pada regangan yang tidak melebihi 5-6\%, sehingga modulus geotekstil harus tinggi. Woven Geotextile yang terbuat dari bahan polyester dapat digunakan pada konstruksi yang membutuhkan kuat tarik dan kekakuan tinggi serta rayapan yang rendah. Jika beban tidak begitu tinggi dan regangan tinggi, maka woven geotextile dari bahan polypropylene dapat digunakan.

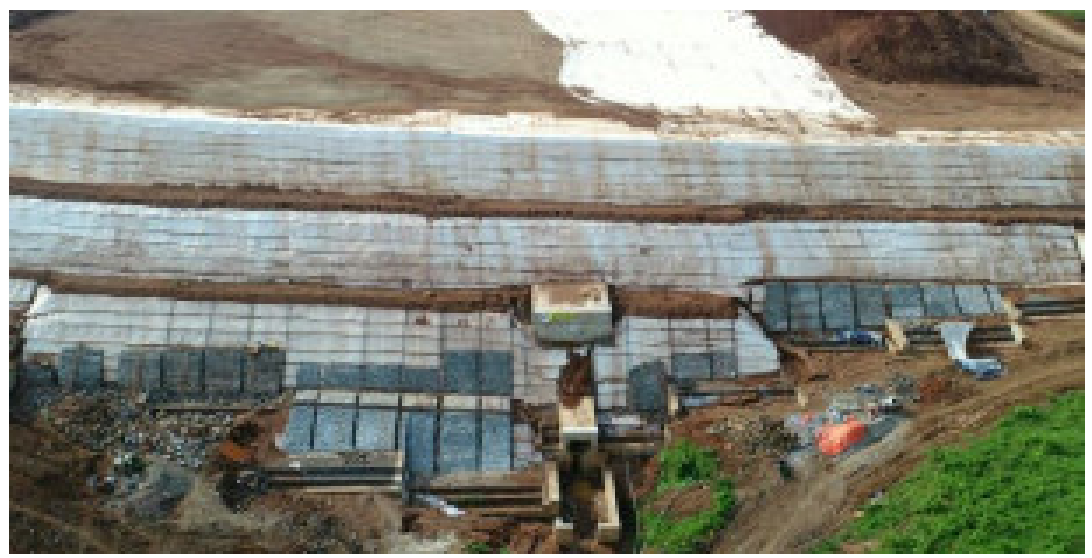

Gambar 7 Aplikasi Geotekstil Sebagai Fungsi Tulangan (Reinforcment)

\section{Fungsi Stabilisasi}

Fungsi stabilisasi pada geotekstil sama saja dengan fungsi perkuatan, hanya saja mekanismenya yang berbeda. Mekanisme pada fungsi ini terjadi ketika gaya vertikal dibebankan pada geotekstil yang diletakkan pada tanah yang mudah berdeformasi.

Mekanisme fungsi geotekstil ini dapat diterangkan pada Gambar 8. Tanah meneruskan gaya ke geotekstil, dan dalam geotekstil berkembang gaya tarik untuk melawan gaya tersebut. Jika geotekstil dipasang di antara tanah dasar dan material urugan, lembaran geotekstil membantu mendistribusikan beban roda yang bekerja di atasnya. Geotekstil mengembangkan tahanan tarik yang kemudian menyebarkan tekanan tersebut ke area tanah dasar yang lebih luas. Hasilnya, kekuatan sistem dalam mendukung beban menjadi bertambah.

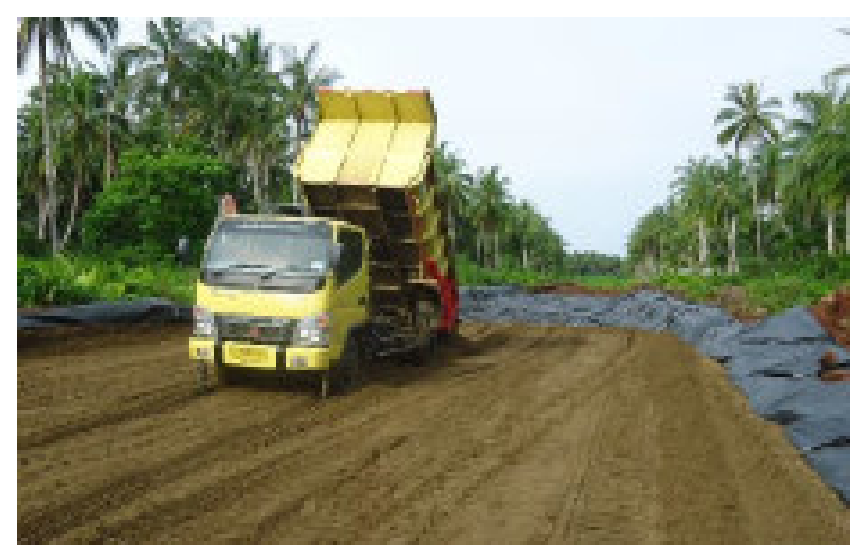

Gambar 8 Aplikasi Geotekstil Sebagai Fungsi Stabilisasi 


\section{Fungsi Proteksi}

Material dasar yang mudah sekali tererosi, seperti lanau, pasir, gambut dan juga material-material kohesif. Erosi ini dapat disebabkan oleh aksi gelombang, kecepatan air atau mengalirnya air dari dalam tanah. Geotekstil yang diletakkan di bawah lapisan pelindung lereng (misalnya rip rap) dapat digunakan untuk perlindungan lereng sungai atau material dasar. Pada tempat pembuangan akhir sampah, geotekstil digunakan sebagai lapis proteksi pada geomembrane. Untuk lapis proteksi properties geotekstil yang perlu diperhatikan yaitu kuat tusuknya. Untuk itu, Non Woven Geotextile yang memiliki kuat tusuk yang besar dapat digunakan sebagai fungsi proteksi.

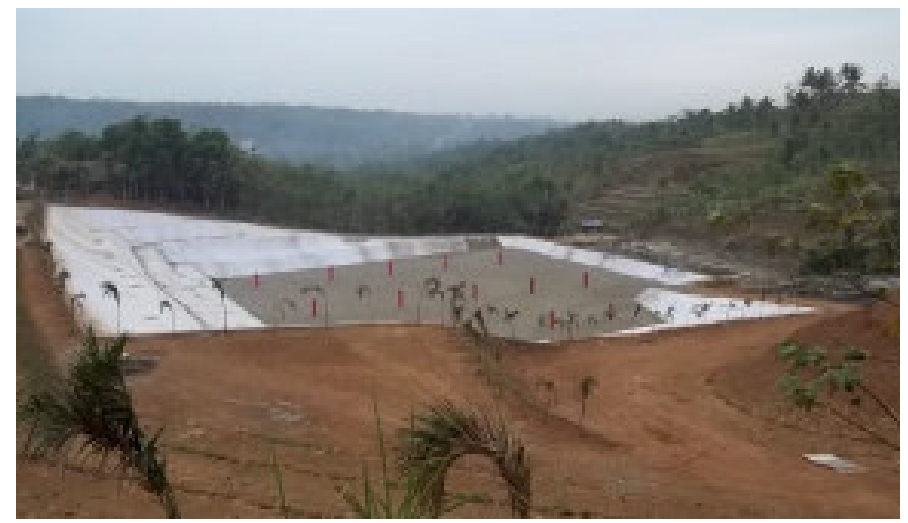

Gambar 9 Aplikasi Geotekstil Sebagai Fungsi Proteksi

\section{Gabungan Fungsi-fungsi}

Geotekstil sering memberikan fungsi ganda atau fungsi-fungsi yang digabungkan. Sebagai contoh, geotekstil bila dipasang di bawah ballast jalan rel akan mempunyai multi-fungsi, yaitu sebagai pemisah, filtrasi, perkuatan dan sekaligus drainase. Untuk maksud ini, seluruh fungsi-fungsi primer, sekunder, dan tersier harus dievaluasi dan semuanya harus memenuhi faktor aman yang diisyaratkan.

Fungsi Gabungan antara lain :

\section{Retaining wall}

Dalam perkembangan teknologi sekarang ini, penggunaan geotextile dapat dikombinasikan dengan bahan-bahan lain untuk perkuatan, seperti kombinasi geotextile dengan baja tulangan wire mesh yang dalam penerapan sebagai struktur retaining wall (dinding penahan), box culvert, dan abutmen jembatan.

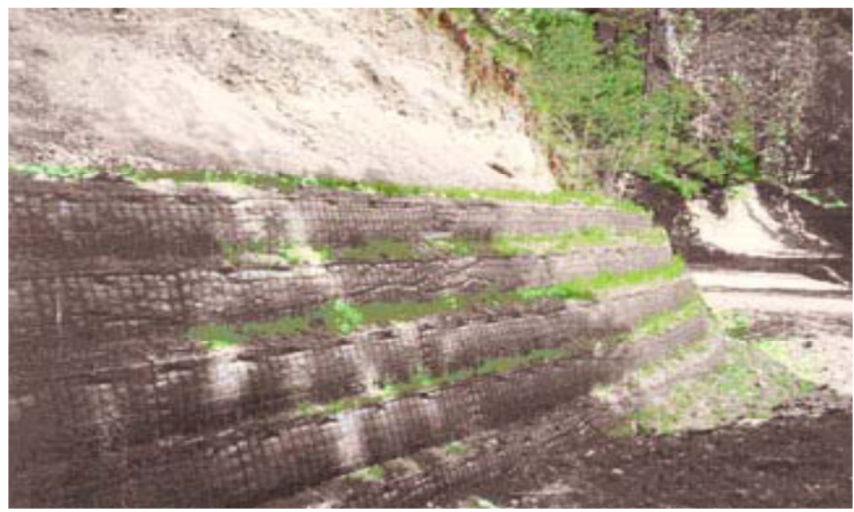

Gambar 10. A Reinforced Soil Retaining Wall

Pada saat ini geotextile sangat banyak digunakan untuk mendukung perkuatan pada dinding penahan tanah. Disamping menahan keruntuhan tanah, bersama dinding geotextile juga sebagai dinding permeable sehingga air tanah dapat mengalir dan tidak selalu memberikan penekanan pada dinding. 
2. Geotextile pada abutment jembatan

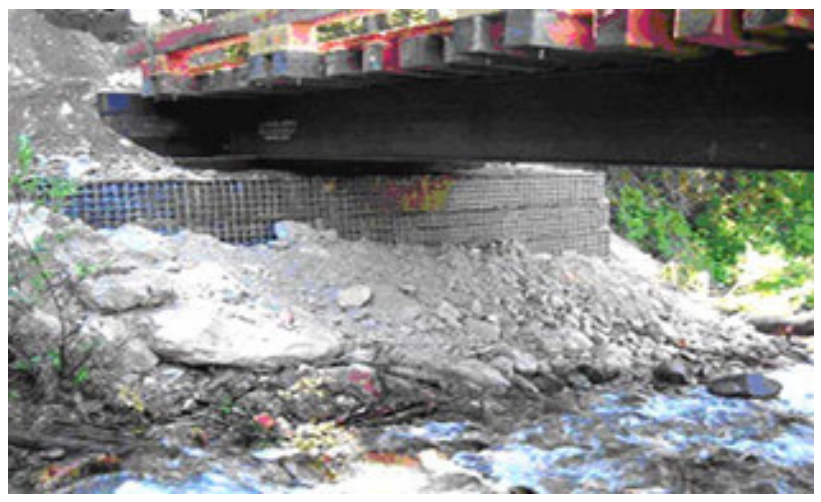

Gambar 11. A Reinforced Soil Bridge Abutment

3. Geotextile yang digunakan untuk box culvert



Gambar 12. A Reinforced Soil Box Culvert or Small Bridge Structure

\section{Sedimen Kontrol}

Geotextile dapat berfungsi sebagai penahan longsoran sedimen dari permukaan lereng yang kemungkinan langsung ke lembah atau sungai dan berdampak terhadap ekosistem baik di sungai maupun di perbukitan.



Gambar 13. Sedimen control 


\section{Waste containment}

Geotextile dapat juga digunakan pada pembuangan sampah. Dikarenakan bahan geotextile permeable sehinga gas-gas yang dihasilkan oleh sampah tidak terkurung yang dapat menyebabkan letupan-letupan.

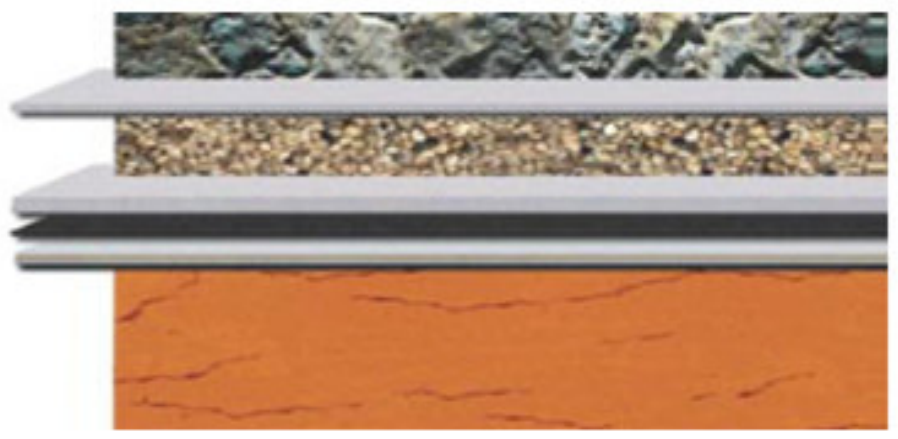

Waste material

Geotextile

Stone

Geomembrane

Compacted clay

Gambar 14. Waste containment

\section{KESIMPULAN}

Berdasarkan hasil kajian tersebut diatas maka dapat disimpulkan:

1) Bahan geotekstil tahan terhadap pelapukan / umur lebih tahan lama, ini merupakan syarat utama bagi bahan-bahan konstruksi dalam tanah.

2) Pelaksanaan pekerjaan konstruksi relatif mudah

3) Bahan ringan mobilisasi relative murah

4) Biaya konstruksi relative murah

\section{DAFTAR PUSTAKA}

Amoco Fabrics and Fibers Company, http://www.geotextile.com

Brown, David, Geotextile Sebagai Penahan Tanah Timbunan."

Geofabrics Astralasia PYT LTD. Australia, www. Geofabrics.com.au

Hardiyatmo, H. C. (2017). Geosintetik Untuk Rekayasa Jalan Raya Perancangan dan Aplikasi. Yogyakarta: Universitas Gajah Mada.

Kenneth .N. Dencher, George.P “ Material for Civil \&Highway Engineering” $4^{\text {th }}$ edision Prentice Hall,1998.

Koerner, R. M. (2005). Designing With Geosynthetics Fifth Edition. New Jersey: Pearson Prentice Hall. Mochtar, Indrasurya B., "Geosynthetics Masa Kini." 